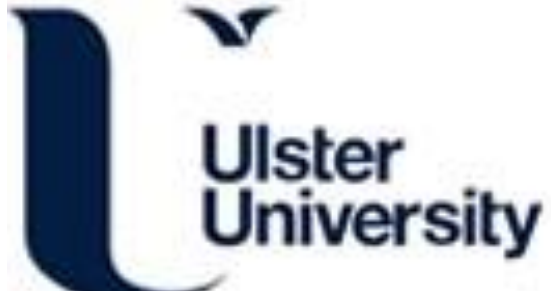

\section{Experimental study on the spread and burning behaviors of continuously discharge spill fires under different slopes}

Zhao, J., Zhu, H., Zhang, J., Huang, H., \& Yang, R. (2020). Experimental study on the spread and burning behaviors of continuously discharge spill fires under different slopes. Journal of Hazardous Materials, $392,1-9$. [122352]. https://doi.org/10.1016/j.jhazmat.2020.122352

Link to publication record in Ulster University Research Portal

\section{Published in:}

Journal of Hazardous Materials

Publication Status:

Published (in print/issue): 15/06/2020

DOI:

10.1016/j.jhazmat.2020.122352

\section{Document Version}

Author Accepted version

\section{General rights}

Copyright for the publications made accessible via Ulster University's Research Portal is retained by the author(s) and / or other copyright owners and it is a condition of accessing these publications that users recognise and abide by the legal requirements associated with these rights.

\section{Take down policy}

The Research Portal is Ulster University's institutional repository that provides access to Ulster's research outputs. Every effort has been made to ensure that content in the Research Portal does not infringe any person's rights, or applicable UK laws. If you discover content in the Research Portal that you believe breaches copyright or violates any law, please contact pure-support@ulster.ac.uk. 
Experimental study on the spread and burning behaviors of continuously discharge spill fires under different slopes Jinlong Zhao ${ }^{\mathrm{a}, \mathrm{b}^{*}}$, Hongqing Zhu ${ }^{\mathrm{a}}$, Jianping Zhang ${ }^{\mathrm{c}}$, Hong Huang ${ }^{\mathrm{d}}$, Rui Yang ${ }^{\mathrm{d}}$ a. School of Emergency Management \& Safety Engineering, China University of Mining \& Technology, Beijing, China

b. Center for capital social safety, People's Public Security University of China c. FireSERT, Belfast School of Architecture and the Built Environment, Ulster University, Newtownabbey, BT37 0QB, United Kingdom d. Institute of Public Safety Research, Department of Engineering Physics, Tsinghua University, Beijing, China

\begin{abstract}
This paper examines the effects of the slope on the burning and spread process of JP-4 continuous spill fires. Spill fires experiments were conducted on surfaces with different slope angles $\left(0^{\circ} \sim 3^{\circ}\right)$ in a rectangular trench $(0.8 \mathrm{~m} \times 6 \mathrm{~m})$. The spread and burning behaviors including the spread process, burning rate and flame height are recorded and analyzed. The results indicate that the whole spread process can be divided, based on the burning area variations with time, into four phases: 1) burning layer spread, 2) shrink process, 3) steady burning, and 4) extinguishment. The results also show that a large slope can increase the spread rate and as a result shorten the duration of the burning layer spread and shrink process pphases. In addition, it is found that the slope has a more significant effect on the maximum spread area than the steady burning area. The steady burning rate decreases with increasing slope and the ratio of the steady burning rate of a spill fire and that of the corresponding pool fire is nearly constant. The flame height of continuous spill fires is also well predicted by an empirical model with a dimensionless heat release rate and equivalent pool diameter. The experimental data presented in the work will provide a basis for further studies of liquid fuel spill fire on an inclined surface.
\end{abstract}

Key words: continuous spill fires, slope angle, spread process, burning rate, flame height 


\begin{tabular}{|c|c|c|c|}
\hline \multicolumn{2}{|c|}{ Nomenclature } & $w$ & Thickness decrease per time \\
\hline$a$ & Absorbed coefficient, $\mathrm{m}^{-1}$ & \multicolumn{2}{|c|}{ Greek symbols } \\
\hline$c$ & Specific heat capacity, $\mathrm{J} /(\mathrm{kg} \cdot \mathrm{K})$ & $\sigma$ & Surface tension, N/m \\
\hline$H_{c}$ & Heat of combustion, $\mathrm{kJ} / \mathrm{kg}$ & $\beta$ & Absorption extinction coefficient \\
\hline$h$ & Thickness of fuel, $\mathrm{m}$ & $\rho$ & Density, $\mathrm{kg} / \mathrm{m}^{3}$ \\
\hline $\mathrm{k}$ & A constant & $\theta$ & Contact angle \\
\hline $\mathrm{L}$ & Length of spread, $\mathrm{m}$ & \multicolumn{2}{|c|}{ Subscripts } \\
\hline Q & Discharge rate, $\mathrm{L} / \mathrm{s}$ & $t$ & Real time \\
\hline$\dot{Q}$ & Heat release rate, $\mathrm{kW}$ & $\min$ & Minimum value \\
\hline $\mathrm{q}$ & Heat flux, $\mathrm{kW} / \mathrm{m}^{2}$ & steady & Steady burning \\
\hline $\mathrm{S}$ & Burning area, $\mathrm{m}^{2}$ & $\mathrm{rad}$ & Heat radiation \\
\hline $\mathrm{T}$ & Temperature, $\mathrm{K}$ & $\operatorname{cov}$ & Heat convection \\
\hline W & Width of trench, $\mathrm{m}$ & $\operatorname{cod}$ & Heat conduction \\
\hline
\end{tabular}

31

\section{Introduction}

One of major hazards of liquid fuels during their transportation, processing and storage is that they can be relatively easily involved in leakage which will then be turned into continuous spill fires after ignition in the presence of an ignition source such as sparks [1,2]. For continuous spill fires, as the spreading area is not confined completely by horizontal physical boundaries, most liquid burning fuels will spread in downhill direction $[3,4]$. In the development of spill fire accidents, the spreading process is usually followed by high flame temperatures and large radiative heat fluxes to adjacent objects, thus posing a huge threat to nearby facilities and further triggering accident escalation, which is commonly known as the domino accident [5]. This was demonstrated in a serious spill fire accident that occurred in April 6, 2015 at Gulei of Fujian Province (a Chinese city). It was reported that the liquid fuel from a pipe leakage was ignited and then flowed to a low terrain place leading to three adjacent storage tanks collapsing and more than ten persons injured [6]. In actual accidents, the development of continuous spill fires is closely related to the ground slope which directly determines the spread and burning process. Moreover, the development of spill fire accidents also determines the proper firefighting time and corresponding measures. Therefore, it is meaningful to investigate the development of spill fires and analyze the detail spread process, particular for the spread on slope surface. 
In the last decades, liquid fuel spread and pool fire burning have attracted significant interest among researchers [7-10]. These studies were focused on either liquid layer spread without ignition or burning rate with a fixed boundary. However, in most fire accidents involving liquid fuels, the fuels tend to spread while burning, particularly for the liquid fuel transportation process [3,4]. To date, the research on continuous spill fires is relatively limited, particular for the continuous experiments. Gottuk et al. [3] conducted continuous spill fire experiments on a concrete surface using JP-5 and JP-8, and they found that the mass burning rate of continuous spill fires is around $20 \%$ than that of pool fires with the same surface area. Benfer [11] performed a series of systematical spill fire experiments using different substrates and fuels [11] and found that the properties of both the substrate and fuel contribute to the lower burning rate and subsequently introduced a coefficient to account for the burning rate for instantaneous spill fires [11]. The spread behaviors of continuous spill fires were examined in $[12,13]$ by performing continuous spill fire experiments on water surface in a rectangular trench $(1 \mathrm{~m} \times 12 \mathrm{~m})$ and the whole spread process can clearly be characterized by different phases.

The aforementioned studies on spill fires were all performed on a flat surface. However, the spread on inclined surface are one of the most common scenarios in real spill fire accidents $[14,15]$. Ingason investigated the continuous gasoline burning rate on the concrete surface and observed that the averaged heat release rate decreases with the increase of slope [15]. Li et al. studied experimentally the continuously released nheptane spill fire in a steel trench $(3 \times 0.15 \mathrm{~m})$, with five different slopes [16], in which five phases of spill fire were divided and characterized according to the real time burning area variations. However, as the width of the trench is relatively small, the burning rate is controlled mainly by convection, which would be very different from the real fire accident scenarios, in which radiation will be the dominating factor. Moreover, the fuel spread on the concrete surface or the iron surface cannot be controlled well and therefore the real burning area cannot be measured accurately. Clearly, the effects of the slope on the spread and burning behaviors of continuous spill fires, especially on the inclined surface, are still little known and should be further 
studied as noted by several researchers [3,4,13-17].

To fill this knowledge gap, this work aims to examine and characterize experimentally the spread and burning behaviors for the continuous spill fires using surfaces with varying slope angles. A series of 15 continuous spill fire tests was carried out on a rectangular surface. The real time burning area, the maximum and steady burning area, burning rate and flame height were measured. The effects of the slope on these parameters are discussed and analyzed.

\section{Experimental setup}

As depicted in Fig.1, an open rectangular trench was used in the tests with a dimension of $6 \mathrm{~m}$ long by $0.8 \mathrm{~m}$ wide. The bottom is made of fireproof glass because it can provide a perfectly flat surface, which can guarantee the even distribution of the fuel layer on the surface as shown in Fig.2. The detail description of the experimental platform is given in [17]. In the tests, the glass surface slope can be controlled and adjusted by the six brackets installed under the trench, as shown in Fig.1 (d). The slope angle was measured and examined before the start of each test by using a digital angle ruler (BOSCHDNM60L). After the adjustment of the platform, preliminary tests without ignition were conducted to ensure uniform spreading of the fuel. The detail spread process is shown in Fig.2. During the tests, a peristaltic pump (WT600-3J) was used to provide a steady volumetric flow rate ranging from $4.2 \mathrm{~mL} / \mathrm{min}$ to $6000 \mathrm{~mL} / \mathrm{min}$. An electronic balance was put under the fuel tank to record the mass loss rate and to ensure that the peristaltic pump can provide a steady flow. The discharge rate was calculated by mass loss measured by the electronic balance and the detail values for all the tests are shown in Table.2. 
105

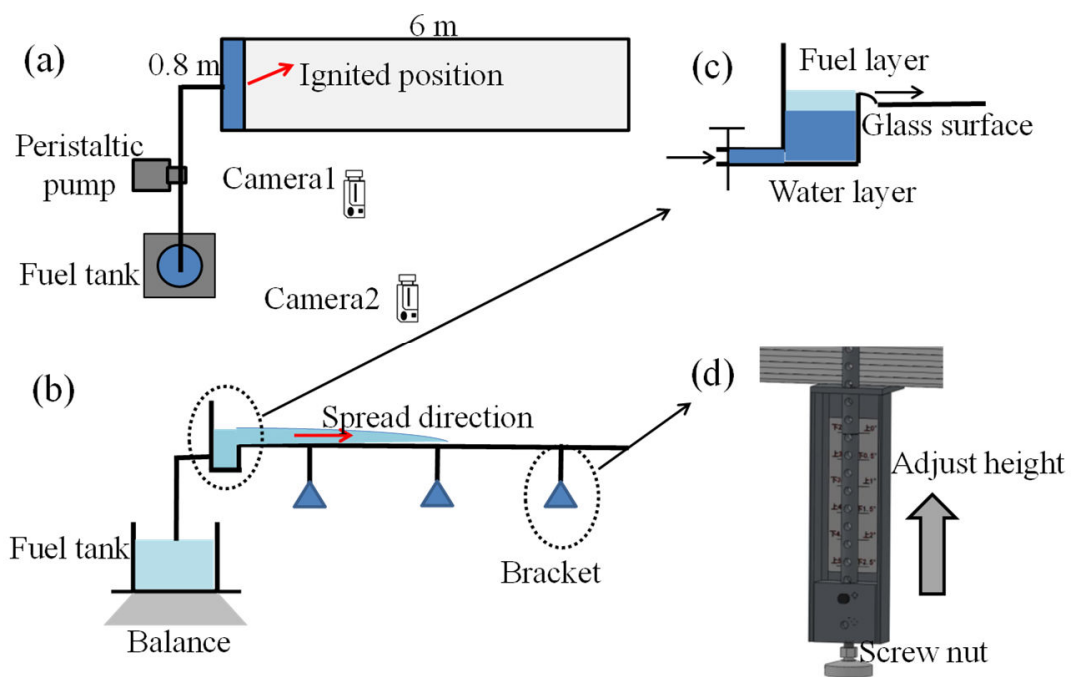

Fig. 1. Schematic diagram of the continuous spill fire experiment platform. a) Top view; b) Sectional view; c) Structure of spill sump; d) Bracket.

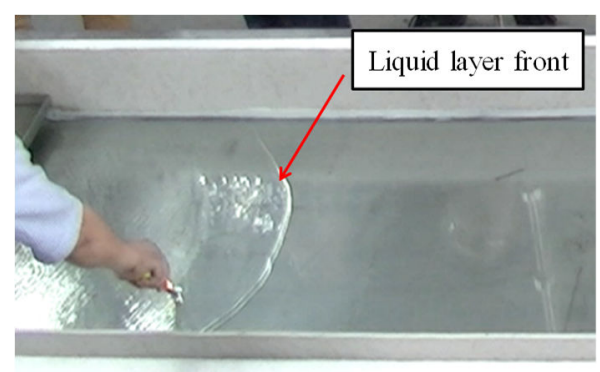

Fig. 2. Liquid layer front after the levelling in a pre-test

In order to reduce the initial fuel velocity from tube, a spill flume was designed, in which the liquid fuel was introduced by gravity, shown in Fig.1 (c). In addition, some water layer was added in the sump to cut off the connection between the burning surface and the fuel tube to reduce the experimental risk. Two cameras were used to record the whole process and to determine the real time spread front position and the flame height. The camera one was located at a high place and the lens tilted at an angle so that the front of the liquid layer could be captured clearly. The other camera located at distance ( $\sim 10 \mathrm{~m})$ to mainly record the flame height. Reference rulers in vertical and horizontal directions were used in experiments to calibrate the position of liquid layer front and the flame height, as illustrated in Fig. 3. 


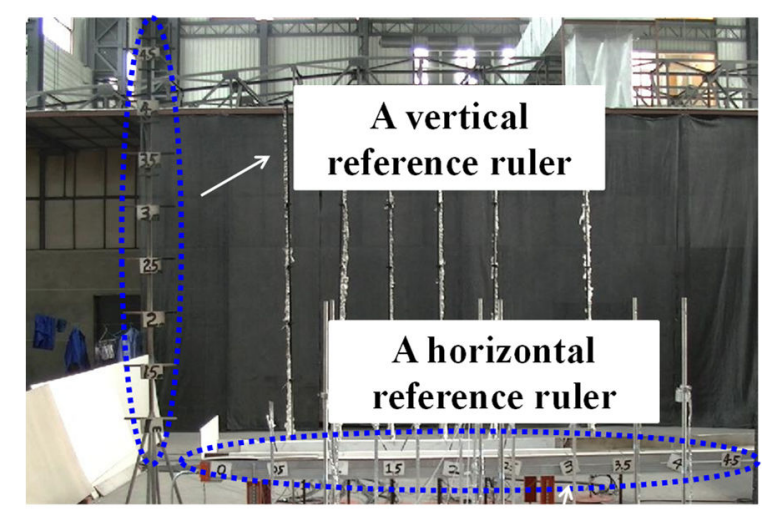

Fig. 3. The layout of the reference rulers in the tests

The flame shape was determined based on the difference between the flame and the background in red, green and blue (RGB) values of each pixel in pictures from the video recording, as commonly done in literature [e.g., 12,16-18]. A schematic diagram of the flame processing is given in Fig.4.

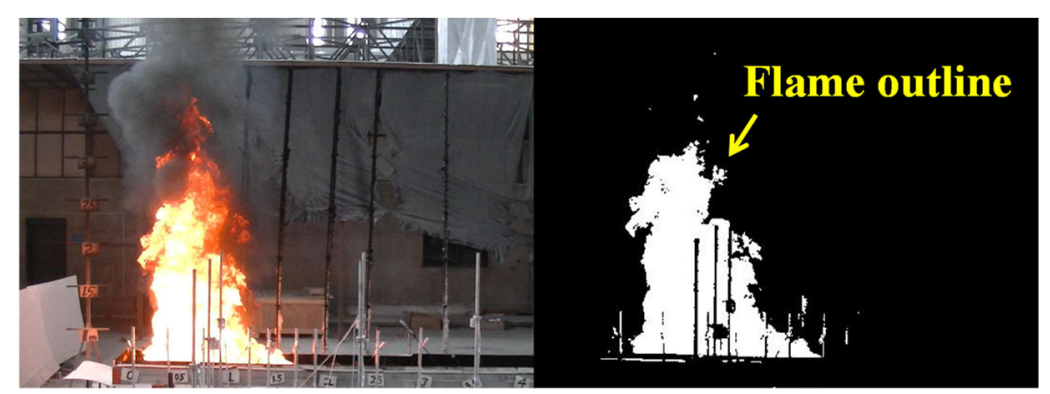

Fig. 4. A schematic diagram of the flame processing method $(R>200, G>100, B>50)$

In the tests, JP-4 was selected as the discharge fuel and a small amount of heptane $(10 \mathrm{~mL})$ was injected on the fuel surface to ignite the discharge fuel. As soon as the fuel spread on the glass surface, the heptane was ignited by an electric spark. The properties of JP-4 are shown in Table 1.

Table 1. The properties of JP-4 in tests [19]

\begin{tabular}{c|c}
\hline Density $\left(\mathrm{kg} / \mathrm{m}^{3}\right)$ & 790 \\
\hline Burning rate of infinite diameter $\left(\mathrm{kg} / \mathrm{m}^{2} \mathrm{~s}\right)$ & 0.051 \\
\hline$k \beta$ value & 3.6 \\
\hline Heat of combustion $(\mathrm{MJ} / \mathrm{kg})$ & 43.5 \\
\hline
\end{tabular}

The ambient temperature was around $26 \pm 4{ }^{\circ} \mathrm{C}$. The tests were conducted in a quiescent environment with no wind and at atmospheric pressure. The slope angle was 
set from $0^{\circ}$ to $3^{\circ}$. It is worth noting that larger slopes $\left(>3^{\circ}\right)$ were also used in preliminary tests but it was found that the liquid layer could not spread uniformly in these tests because surface tension is overcome by gravity. The discharge rate can be controlled by the change of the rotation speed of the peristaltic pump. The detail experimental configurations are given in Table 2.

Table 2. Specification of the testing configurations

\begin{tabular}{ccccc}
\hline No. & $\theta\left(^{\circ}\right)$ & $\begin{array}{c}\text { Revolutions per } \\
\text { minute }(\mathrm{rpm})\end{array}$ & Discharge rate(L/min) & Discharge time(s) \\
\hline Test-1 & 0 & 50 & 0.93 & 208 \\
Test-2 & 0 & 100 & 2.05 & 201 \\
Test-3 & 0 & 150 & 3.01 & 198 \\
Test-4 & 0 & 200 & 4.39 & 202 \\
Test-5 & 0.5 & 50 & 0.93 & 186 \\
Test-6 & 0.5 & 100 & 2.05 & 194 \\
Test-7 & 0.5 & 150 & 3.01 & 179 \\
Test-8 & 0.5 & 200 & 4.39 & 180 \\
Test-9 & 1 & 50 & 0.93 & 186 \\
Test-10 & 1 & 100 & 2.05 & 191 \\
Test-11 & 1 & 150 & 3.01 & 189 \\
Test-12 & 1 & 200 & 4.39 & 176 \\
Test-13 & 3 & 50 & 0.93 & 182 \\
Test-14 & 3 & 100 & 2.05 & 191 \\
Test-15 & 3 & 150 & 3.01 & \\
\hline
\end{tabular}

\section{Result and discussion}

\subsection{Spread process}

The fuel started to spread on the rectangular glass surface as soon as the pump was 146 turned on. Due to the difference in the discharge rate and the burning consumption 147 (change in thickness per unit time $\times$ spread area), the burning area varies significantly 
with time for the whole spread process. In order to clearly display the whole spread process, Test- $8\left(Q_{i n}=4.39 \mathrm{~L} / \mathrm{min}\right)$ is selected as an example to show the detailed spread process in Fig. 5.

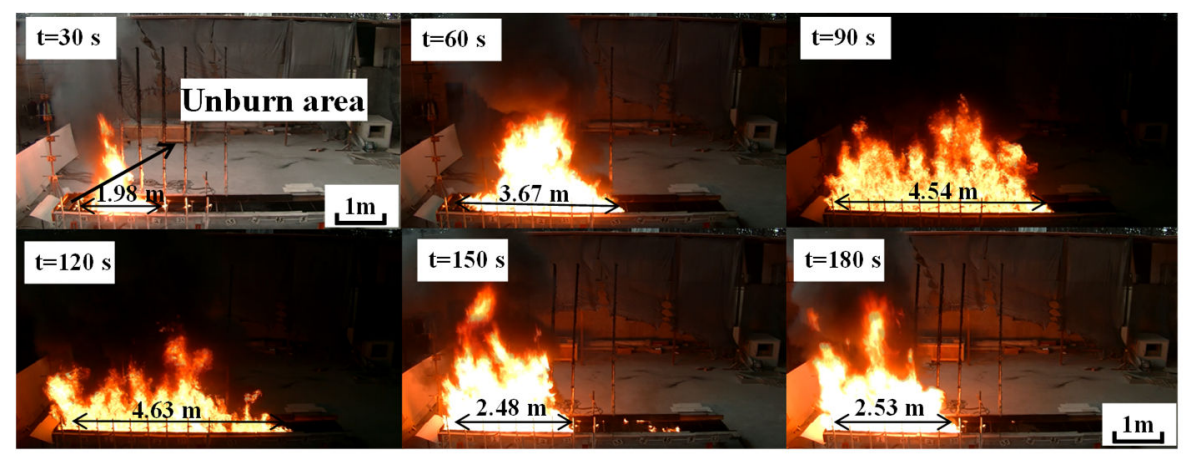

Fig. 5. Images of continuous spill fire at some moments after discharge in Test 8

From the time of discharge $t=0 \mathrm{~s}$ to the time $\mathrm{t}=30 \mathrm{~s}$, we can observe that the fuel spread fast and the flame only covers a small part of the liquid surface which means that most of the fresh fuel was not burning in this period $(0 \mathrm{~s}<\mathrm{t}<30 \mathrm{~s})$. The flame was small and gradually spread on the whole liquid surface in this period. As the spread continues $(60 \mathrm{~s}<\mathrm{t}<120 \mathrm{~s})$, the burning area continued to increase and the spread length reached its maximum (around $4.63 \mathrm{~m}$ ) at $\mathrm{t}=120 \mathrm{~s}$. In this period, the flame occupied the whole liquid surface and the flame height also achieved the maximum value. Considering the large burning area and flame height, we can conclude that the burning consumption (burning area $\times$ burning rate) played an important role in this period. Subsequently, the burning area started to shrink due to the burning consumption higher than the discharging rate, and reached a nearly constant value at around $t=150 \mathrm{~s}$, corresponding to the equilibrium conditions, when the burning consumption becomes the same as the discharging rate. These spread behaviors were also observed in the other tests.

Figure 6 shows the real time front position of the liquid layer obtained by the video analysis. The results indicate that the spread and burning behaviors can be characterized by four distinct phases (namely burning layer spread, shrink process, steady burning and extinguishment) appearing in succession in consistence with visual observations in Fig. 5. The burning layer spread phase corresponds to the fire growth process in which the burning area increases with time and the burning area reaches a maximum at the 
end of this phase. The shrink phase corresponds to the decrease of the burning area due to the burning consumption larger than the fuel supply rate. The shrink phase is relatively short, which is followed by nearly constant burning area, which corresponds to the steady burning phase. Finally, after the stop of fuel supply, the fire gradually disappears in the extinguishment phase.
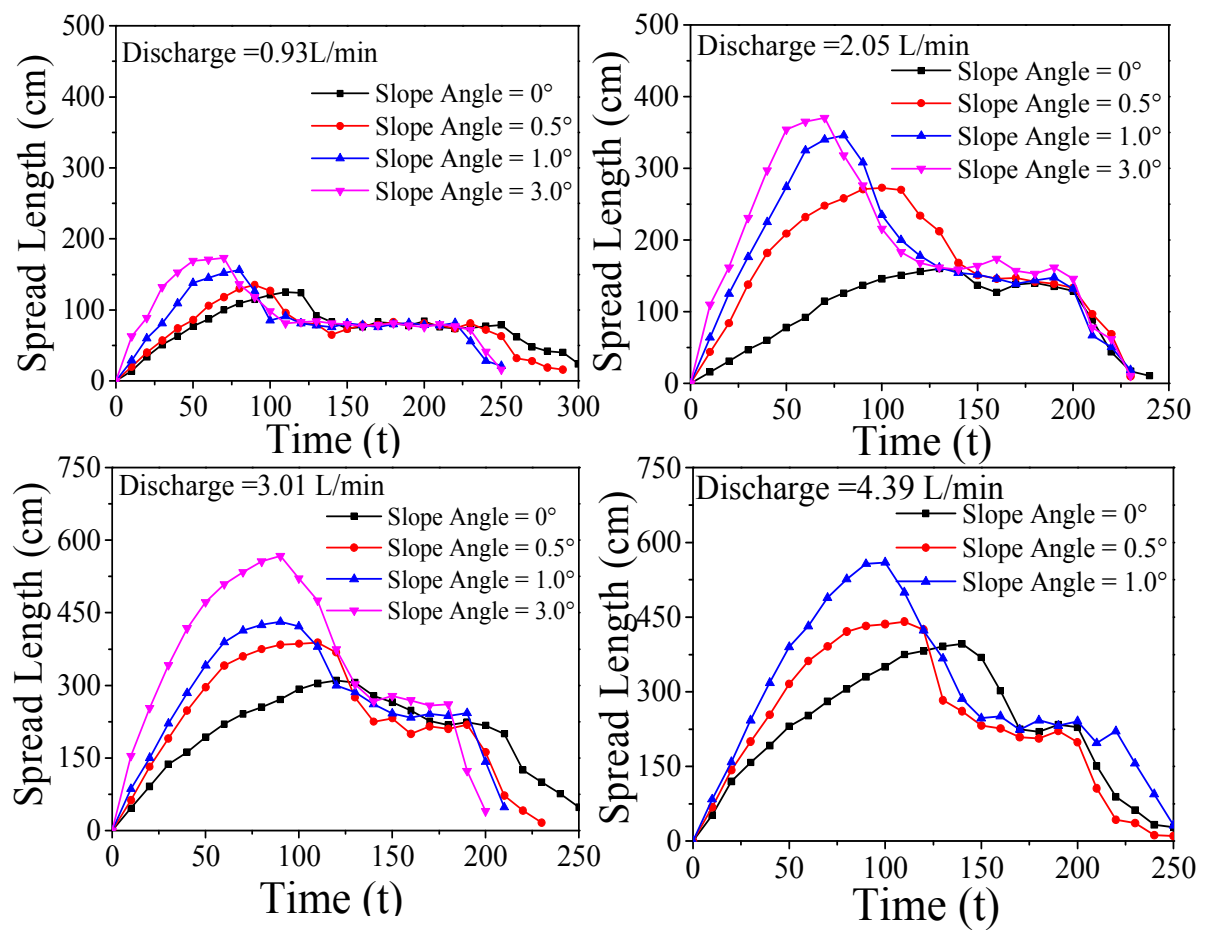

Fig. 6. The front position of liquid layer as a function of time for some spill fire tests with different slope angles

Comparing the spread process on the different slopes, it can be observed that the division of the spread phase is independent of the slope angle. However, the detailed characteristics including the burning area, burning rate or spread rate in each phase are different and need to be discussed in detail. The phase division of whole spread process is meaningful to clearly know the development of continuous spill fire accidents and then further analyze the main physical mechanism related to spread and burning behaviors. In addition, the unbalance between discharge rate and burning consumption still exist, which determines these spread phases in the tests will be present in practical accidental spill fire scenarios. For clarity we summarize here the main spread process and the schematic is shown in Fig.7. 


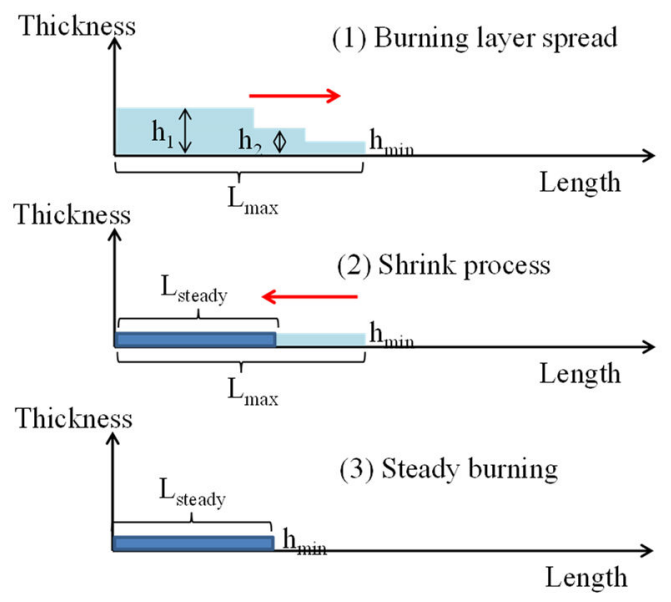

Fig. 7. The diagram of the main spread process $\left(h_{1}, h_{2}\right.$ and $h_{\min }$ are the fuel thickness at the different times, $\mathrm{L}$ is the fuel spread length)

In the simplified processes, the fuel thickness gradient with the spread length is not considered and this assumption has been widely used in some studies [20-22]. In the burning layer spread phase, gravity is a main force to drive the liquid layer spread, which is associated with the fuel thickness. And the real-time average thickness $(h)$ can be expressed as:

$$
h=\frac{Q_{i n} t-\int_{0}^{t} w(t) S(t) d t}{S}
$$

where $Q_{\text {in }}$ is the fuel discharge rate, $S$ is the burning area, and $w(\mathrm{t})$ is the burning rate (thickness decrease per unit time, $\mathrm{m} / \mathrm{s}$ ). It has been confirmed in $[7,22]$ that the liquid layer will stop spreading when the liquid layer thickness $(h)$ equals to the minimum value $\left(h_{\min }\right)$ indicating the end of the burning layer spread phase. The minimum thickness is controlled by the balance between surface tension and gravity for spread on a flat surface [22-24]. The minimum thickness on a flat surface can be expressed as:

$$
h_{\text {min }}=\sqrt{\frac{2 \sigma(1-\cos (\theta))}{\rho g}}
$$

where $\rho$ is the density of the fuel, $\theta$ is the contact angle, and $\sigma$ is the surface tension. It should be noted that the above parameters need to be revised for ignited conditions in the quantitative analysis. For an inclined surface, this value will decrease with an increase in the slope as shown experimentally in [25,26], although the detailed value of the minimum thickness for an inclined surface is still unknown. For liquid layer spread, an empirical model has been provided by PHAST to calculate the spread rate on a flat 
surface.

$$
\frac{d L}{d t}=k \sqrt{g\left(h-h_{\min }\right)}
$$

where $k$ is a spread constant $(k=2)$ in a flat surface [27]. Based on Eqs.(1-3), it can be concluded that the burning layer spread phase for continuous spread on a solid surface is controlled primarily by the discharge rate, the burning rate and the minimum thickness.

In the shrink process phase, there is no fresh fuel to supply to the front layer because the burning consumption is larger than the discharge rate. In this phase, the thickness of liquid layer reaches its minimum value. So the duration can be simplified under the condition that the thickness gradient in the horizontal direction can be neglected as

$$
t_{1}=\frac{h_{\min }}{w_{t}}
$$

In the steady burning phase, the burning area is nearly constant as the burning consumption is the same as the discharge rate. Therefore the controlling equation in this phase can be written as:

$$
\mathrm{w}_{\text {steady }} \mathrm{S}_{\text {steady }}=Q_{\text {in }}
$$

where $\mathrm{S}_{\text {steady }}$ and $\mathrm{w}_{\text {steady }}$ are respectively the burning area and burning rate in the steady burning phase. This method has been used in poo fires, in which the supply rate equals to the burning consumption rate in the steady burning stage [26].

Table 3 shows that the duration of burning layer spread phase decreases with the increase of slope for the tests with the same discharge rate. This can be explained by examining Eqs.(1-3), where we have deduced that the spread rate will be higher on a inclined surface due to the lower minimum thickness and gravity, which will result in a quick decrease of the fuel thickness. Furthermore, the burning consumption also increases due to the increasing burning surface area. The duration of the shrink phase tends to decrease with the increase of slope, because the thickness will be shallower on a larger slope surface. In the shrink process, there is no fresh fuel supplied to the front layer due to a larger burning consumption and as a result, the shallower liquid layer will lead to a shorter burning duration.

Table 3. The duration of burning layer spread and shrink process stages 


\begin{tabular}{cccccc}
\hline Test & $\begin{array}{c}\text { Spread stage } \\
\text { duration (s) }\end{array}$ & $\begin{array}{c}\text { Shrink stage } \\
\text { duration(s) }\end{array}$ & Test & $\begin{array}{c}\text { Spread stage } \\
\text { duration (s) }\end{array}$ & $\begin{array}{c}\text { Shrink stage } \\
\text { duration(s) }\end{array}$ \\
\hline 1 & 116 & 38 & 9 & 82 & 29 \\
2 & 128 & 35 & 10 & 86 & 25 \\
3 & 134 & 40 & 11 & 107 & 29 \\
4 & 152 & 39 & 12 & 110 & 27 \\
5 & 96 & 31 & 13 & 65 & 18 \\
6 & 106 & 36 & 14 & 76 & 22 \\
7 & 107 & 33 & 15 & 82 & 21 \\
8 & 126 & 37 & & & \\
\hline
\end{tabular}

243 Figure 6 also shows that the burning area will change greatly with a change in the 244 slope. The maximum burning area and the steady burning area are known as the two 245 key parameters to determine the open fire damage and thermal hazard risk [2,28]. The 246 values of the maximum $\left(S_{\max }\right)$ and steady burning areas $\left(S_{\text {steady }}\right)$ obtained for all the tests 247 are shown in Table 4. In addition, a ratio to define the relative difference between $S_{\max }$ 248 and $S_{\text {steady }}\left(r_{s}=\frac{S_{\text {max }}-S_{\text {steay }}}{S_{\text {steay }}}\right)$ is also introduced to show the range of variations.

249 Table 4. The maximum and steady burning area under different tests

\begin{tabular}{cccccccc}
\hline No. & $S_{\max }\left(\mathrm{m}^{2}\right)$ & $S_{\text {steady }}\left(\mathrm{m}^{2}\right)$ & $r_{s}$ & No. & $S_{\max }\left(\mathrm{m}^{2}\right)$ & $S_{\text {steady }}\left(\mathrm{m}^{2}\right)$ & $r_{s}$ \\
\hline Test-1 & 0.98 & 0.62 & 0.58 & Test-9 & 1.59 & 0.69 & 1.30 \\
Test-2 & 1.66 & 1.10 & 0.50 & Test-10 & 2.42 & 1.10 & 1.20 \\
Test-3 & 2.30 & 1.71 & 0.34 & Test-11 & 3.36 & 1.56 & 1.16 \\
Test-4 & 3.06 & 2.28 & 0.33 & Test-12 & 4.38 & 2.24 & 0.95 \\
Test-5 & 1.44 & 0.65 & 1.21 & Test-13 & 1.75 & 0.72 & 1.43 \\
Test-6 & 2.16 & 1.04 & 1.08 & Test-14 & 2.93 & 1.29 & 1.27 \\
Test-7 & 2.89 & 1.48 & 0.94 & Test-15 & 3.85 & 1.70 & 1.26 \\
Test-8 & 3.61 & 2.10 & 0.66 & & & & \\
\hline
\end{tabular}


252 increase with the increasing slope angle for the same discharge rate. However, it can be

253 observed that the maximum burning area is more sensitive to the slope angle compared

254 with the steady burning area. For example, comparing Test 1 and Test 5 the maximum

255 burning area increases by around $41.92 \%$, while for the steady burning area, the

256 increase is less than $4.84 \%$. This directly leads to the increase of $r_{s}$ with the increase of

257 slope.

$258 \quad 3.2$ Burning rate

259 Although we can't measure the instantaneous burning rate, it is possible to calculate 260 using Eq.(5) the burning rate in the steady burning phase from the burning area and the 261 discharge rate. Fig.8 plot the steady burning rate as a function of the fire equivalent 262 diameter which is calculated based on the spread length and the width of trench. It can 263 be observed that the steady burning rate increases with the pool diameter. For comparison, we also plot in Fig. 8 the burning rate calculated by the empirical correlation developed from pool fires [29]. It is clear that, while the trends of both sets of data are similar, the burning rate of a spilled fire is systematically lower than that of a pool fire with the same pool diameter, which is in accordance with findings from previous studies $[1,3,12,13]$. In order to explain this difference, it is important to consider the difference in the heat transfer process between pool fires and spill fires as illustrated in Fig. 9.

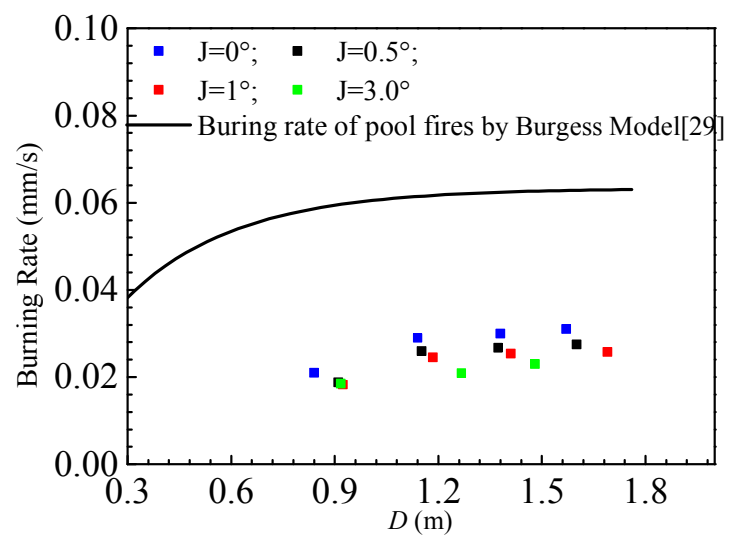



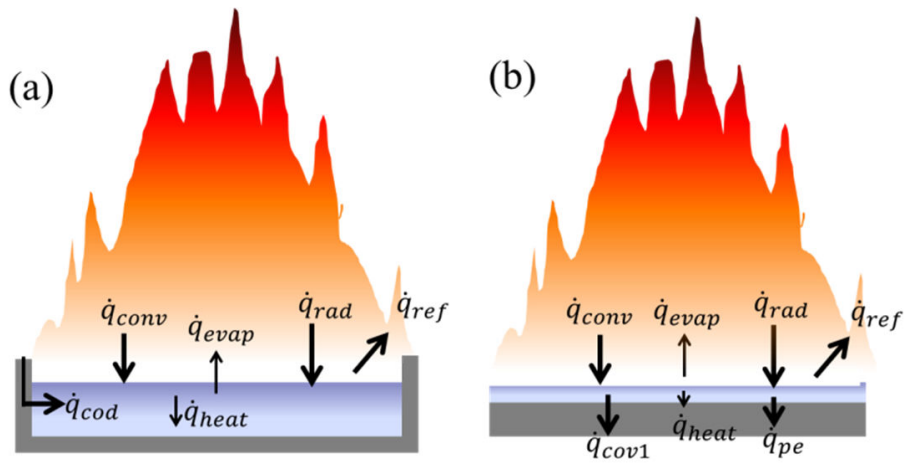

Fig. 9. Schematic of the main heat transfer mechanisms for (a) pool fire burning, adapted from Hamins et al.[30] and (b) spill fire burning

For pool fires, the heat feedback from the flame to the fuel surface is usually completely absorbed by the thick liquid layer and the heat loss between the liquid layer and the pan bottom is negligible [4]. So the burning rate of pool fires can be expressed as:

$$
\dot{W}^{\prime}=\frac{\dot{q}_{r a d}+\dot{q}_{c o v}+\dot{q}_{c o d}-\dot{q}_{r e f}}{\rho\left(c_{p f} \Delta T+L_{v}\right)}
$$

where $c_{p f}$ is fuel specific heat capacity and $L_{v}$ is latent heat of evaporation. For a large burning area $(\mathrm{D}>0.2)$, the heat conduction from the side walls to the liquid layer $\left(\dot{q}_{c o d}\right)$, the radiative reflection $\left(\dot{q}_{\text {ref }}\right)$ and the heat convection $\left(\dot{q}_{c o v}\right)$ between the flame and the liquid surface are usually neglected [30]. So an empirical model based on the radiative heat feedback from flame to surface was proposed by Burgess [29].

$$
\dot{w}_{\text {pool }}^{\prime}=w_{\infty}^{\prime}\left(1-e^{-k \beta D}\right)
$$

where $w_{\infty}^{\prime}$ is the burning rate of an 'infinite' pool diameter (burning thickness per time), $k$ is an absorption extinction coefficient, and $\beta$ is a mean beam length corrector.

In the test, the heat loss of liquid layer is considered as the main reason behind the lower burning rate. The heat loss of liquid layer can be divided into two parts: the radiative penetration (through the liquid layer and the glass) and the heat transfer from the liquid layer to the glass including the convection and conduction. For the burning of pool fires, the radiative heat flux is mainly absorbed by the upper liquid layer $(\sim 3 \mathrm{~mm})$, which results in a thin boiling layer [31]. However, the initial thickness was estimated based on preliminary spread tests (no ignition) to be less than $2 \mathrm{~mm}$ in the present tests, which illustrates that the radiative heat feedback cannot be completely absorbed by the 
spread layer, as verified in our previous studies [17,32]. In fact, the radiative heat feedback can also be divided into two parts: unabsorbed part $\left(q_{n o n-a b}\right)$ and absorbed part $\left(q_{a b}\right)$ in previous studies $[31,32]$. The radiative heat loss of the liquid layer can be expressed as:

$$
q_{\text {radloss }}=q_{\text {non-ab }}+\varepsilon q_{a b} e^{-a h}
$$

where $a$ is an absorption coefficient, $h$ is the thickness of the liquid layer and $\varepsilon$ is the transmittance ratio of the fireproof glass.

The heat transfer process between the liquid layer and the glass will be more obvious due to the thin liquid layer and the movement of the fuel. In the quantitative analysis, it is difficult to directly calculate this heat loss part due to the coupling effects of radiation and fuel movement. However, the temperature of the bottom glass can represent the heat transfer process in qualitative because the radiation effect on the glass temperature increase can be neglected. Therefore, the transfer heat flux between the liquid layer and the glass surface due to the convection and the heat conduction can be expressed as:

$$
q_{\text {loss } 2}=m c_{\text {pglass }} \Delta T
$$

where $m$ is the glass mass per unit area in the tests, $c_{\text {pglass }}$ is the specific heat of the glass at the atmospheric pressure and $\Delta T$ is the temperature increasing rate of the glass. Combining Eqs.(6-9), the burning rate of continuous spill fires can be deduced as:

$$
\dot{w}_{\text {spill }}^{\prime}=\left(1-\frac{q_{\text {radloss }}+q_{\text {loss } 2}}{\dot{q}_{\text {rad }}}\right) w_{\infty}^{\prime}\left(1-e^{k \beta D}\right) \rho
$$

In the steady burning phase, the fuel thickness has achieved the minimum value, which directly determines the stable of the liquid layer radiative heat loss. In addition, we found that the bottom glass surface temperature nearly kept a constant in the tests, gradually approaching the boiling point at the steady burning phase, which has been observed in [17]. The variation trend of the glass temperature illustrates the transfer process can be approximately considered as a stable process. As a result, the steady burning area in Fig.6 and stable burning rate in Fig. 8 can be observed in the tests.

As mentioned earlier, the increase of the slope angle can lead to a thin liquid layer, which would indicate based on Eq.(8) that $q_{\text {radloss }}$ will increase and subsequently a lower burning rate. This is verified in Fig. 8, which shows that for the same discharge 
rate the larger the slope angle, the smaller the burning rate in the steady phase. In order to compare the burning rate of between the spill fire and pool fire quantitatively, the ratio $\left(\dot{m}_{\text {spill }}^{\prime} / \dot{m}_{\text {pool }}^{\prime}\right)$ is given in Table 5 .

Table 5. The burning rate ratio the same burning size

\begin{tabular}{ccccc}
\hline & $Q_{i n}=0.93 \mathrm{~L} / \mathrm{min}$ & $Q_{i n}=2.05 \mathrm{~L} / \mathrm{min}$ & $Q_{i n}=3.01 \mathrm{~L} / \mathrm{min}$ & $Q_{i n}=4.39 \mathrm{~L} / \mathrm{Min}$ \\
\hline$\theta=0^{\circ}$ & 0.3555 & 0.4661 & 0.4819 & 0.4819 \\
$\theta=0.5^{\circ}$ & 0.316 & 0.4266 & 0.4266 & 0.4345 \\
$\theta=1.0^{\circ}$ & 0.3081 & 0.395 & 0.4029 & 0.4108 \\
$\theta=3.0^{\circ}$ & 0.3002 & 0.3397 & 0.3713 & Non \\
\hline
\end{tabular}

Table 5 shows that the burning rate of spill fires is systematically lower than that of pool fires and the burning rate ratio of spill fires to pool fires is from 0.30 to 0.49 . For the tests with the smallest discharge rate of $0.93 \mathrm{~L} / \mathrm{min}$, this ratio is the smallest. We believe that this is because relative importance of the conduction heat loss in the horizontal direction in the glass is more important in these cases as the spread length is much smaller than those with large discharge rates. This would suggest less energy is available for fuel evaporation. With the increasing fuel discharge rate (and spread length), the importance of this part of heat loss, when compared to the total heat feedback $\left(S \times q_{f}\right)$ from the flame to the liquid layer, will gradually decrease and eventually becomes negligible as we noted in Table 5 that the ratio for higher discharge rates is nearly the same for the same slope angle.

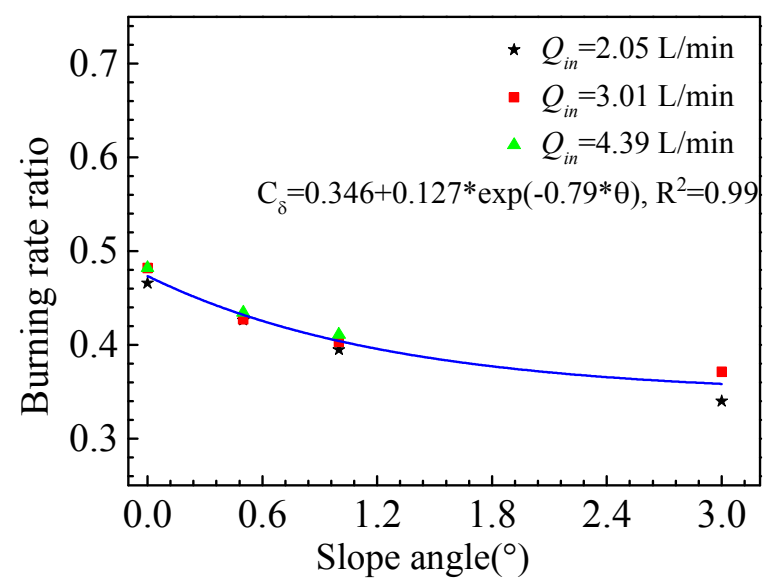


Fig. 10. The burning rate ratio vs the slope angle

Figure 10 shows the variation of the burning rate ratio with the slope angle except for the case with $Q_{i n}=0.93 \mathrm{~L} / \mathrm{min}$ due to its small burning size. All the test data collapse into one single line. The fact that the burning rate ratio becomes nearly constant can be explained by examining the change of the thickness of the liquid layer with the slope angle. With the increasing of slope, the decrease of liquid fuel thickness will gradually become smaller due to the fuel surface tension limitation $[33,34]$. We have shown that the burning rate of spill fires is mainly affected primarily by the fuel thickness. This explains that the burning rate ratio initially decreases with the slope angle but then gradually approaches a constant when the slope angle becomes sufficiently large as shown in Fig.10. It should be noted however that we expect that the relation only holds up to a certain slope angle because if the slope angle becomes too large, the surface tension will be overcome by gravity and the fuel will not spread evenly on the glass surface, resulting in a discontinuous spread area, as we found in some preliminary tests.

\subsection{Flame height}

Flame height is a key parameter in the liquid fire and is closely related to the surrounding radiative distribution $[4,9]$. The flame height was determined by analyzing the digital images as discussed earlier. Fig.11 shows the experimental results of the flame height as a function of time for the case with the discharge rate of $2.05 \mathrm{~L} / \mathrm{min}$. The flame height in the whole spread process experiences the following four stages: quick increase, slow decrease, stable and extinguishment. The initial flame height was due to the burning of the ignition source. In general, the flame height variation is consistent with that of the burning area change. The ignition of JP-4 was identified as the appearance of strong black smoke.

It is interesting to note that in the steady burning phase, the flame heights nearly keep constant for the same discharge rate independent of the slope. This is due to the fact that the burning area and the burning rate at the steady burning phase are almost the same for the cases with different slopes but the same discharge rate. However, the flame fluctuations are significant for tests with large slope angles. As mentioned above, the 
374 liquid layer is thin on a large slope angle surface, which results in unsteady burning.

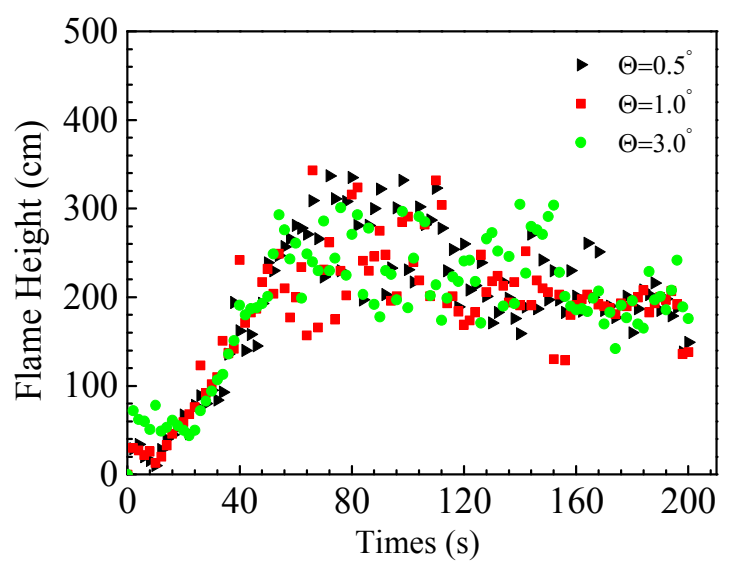

375

Fig. 11. The variation of the flame height as a function of time under the different slopes $\left(Q_{i n}=2.05 \mathrm{~L} / \mathrm{min}\right)$

In the steady burning phase, the ratio of fire length to fire width is less than three and the burning area can approximately consider as a circle pool fire. We can calculate the flame height following as [35]:

$$
H / D=3.7 \dot{Q}^{* 2 / 5}-1.02
$$

where $D$ is the equivalent burning diameter $(2 \sqrt{W L / \pi}), \dot{Q}^{*}$ is the dimensionless heat release rate which is defined as:

$$
\dot{Q}^{*}=\frac{\dot{Q}}{\rho_{0} c_{p a} T_{0} g^{0.5} D^{\frac{5}{2}}}
$$

where $\rho_{0}$ and $T_{0}$ are ambient density and temperature, respectively. $g$ is the gravity acceleration. $c_{p a}$ is the specific heat of air at constant pressure and $\dot{Q}$ is the total heat release rate, which is calculated as:

$$
\dot{Q}=C_{\delta} \dot{m}_{p o o l} H_{c}
$$

where $C_{\delta}$ is a modified coefficient (a ratio between the spill fire burning rate and the pool fire burning rate) and its values are given in Table 5 for all the tests. Fig. 12 shows a comparison of the experimental and calculated flame height. It can be seen that the flame height model can predict well the spill fire flame height with the modified heat release rate. The predicted flame heights are generally slightly lower than the experimental values. This could be due to the non-uniform burning rate on the whole burning surface as we observed that during the tests the burning near the front and back 
of the spill pool is less intense than that in the center region. This implies that the equivalent pool diameter is overestimated by the model and as a result based on Eq.(11) underestimated flame height.

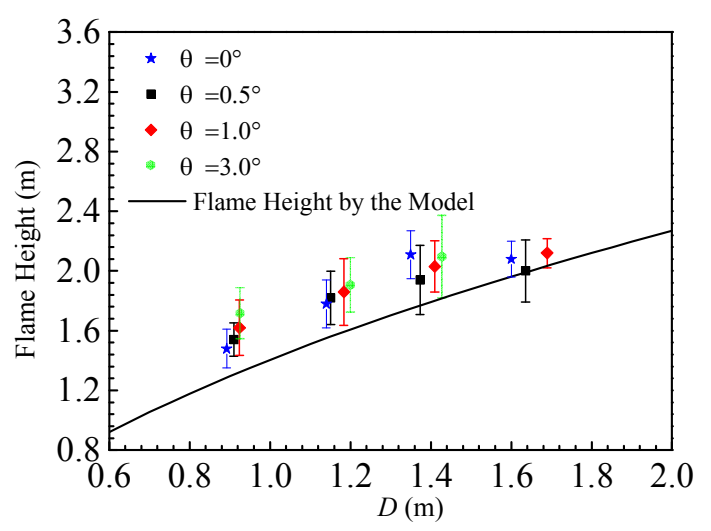

Fig. 12. The calculated flame height with respect to the burning diameter in comparison with the measured values in tests

\section{Conclusion}

The spill fires experiments with different discharge rates were conducted on a rectangular glass surface with varied slope angles. The effects of the slope on the spread and burning behaviors are analyzed and summarized.

For the spread behaviors of spill fires, the whole spread process can be divided into four phase: 1) burning layer spread phase; 2) shrink phase; 3) steady burning phase and 4) extinguishment, independent of the slope angle. However, the duration and the burning area vary greatly with the slope angle. The durations of the burning layer spread phase and shrink phase decrease with the increase in the surface slope angle. It was also found that the slope has a more important effect on the maximum burning area than the steady burning area, resulting in an increase of the relative difference, $r_{s}=\frac{S_{\text {max }}-S_{\text {steay }}}{S_{\text {steay }}}$ ) with increasing slope angle.

For the burning behavior, the burning rate of a spill fire was found to be systematically lower than that of a pool fire for the same burning size and the burning rate ratio ranges from 0.30 to 0.49 . It was found that the spill fire burning rate at the steady burning phase decreased with an increase of the slope angle because the shallow liquid fuel would result in a large heat loss of the liquid layer. The burning rate ratio 
between the spill fire and corresponding pool fire was introduce to characterize the effects of slope on the burning rate and it was found that the burning rate ratio initially decreases with the slope angle but then approaches a nearly constant for large slopes because of the smaller variation of the fuel thickness with an increase of the slope angle. A correlation between the burning rate ratio and slope angle is also deduced.

The flame height in the steady burning phase was found to increase with increasing equivalent fire diameter. It was also shown that the flame height correlation developed for pool fires can be used to predict spill fires after the heat release rate is modified using the burning rate ratio, provided that the ratio of fire length to fire width is less than three.

We have presented in this work a detailed study of the effects of the slope on the spread and burning behaviors of continuous spill fires. The analysis of the spread process and the determination of some key parameter can provide some guidance in thermal hazard risk assessment in actual spill fires accidents. Moreover, the experimental data can be used to further develop numerical models for prediction of continuous spill fires. However, more experiments, especially on different substrates, should be conducted to address the continuous spill fire issue.

\section{Acknowledgements}

This study was sponsored by the National Key R\&D Program of China ( No. 2018YFC0808100), the National Natural Science Foundation of China (No. 51906253) and the Opening Funds of State Key Laboratory of Building Safety and Built Environment and National Engineering Research Center of Building Technology (BSBE 2017-03).

\section{References}

[1] C. Mealy, M. Benfer, G. Dan, Liquid Fuel Spill Fire Dynamics, Fire Technol., 50 (2014), pp. 419-436.

[2] S. Brambilla, D. Manca, Accidents involving liquids: A step ahead in modeling pool spreading, evaporation and burning. J. Hazard. Mater., 161(2-3)(2009), pp. 1265-1280. [3] D.T. Gottuk, D.A. White. Liquid fuel fires. In: SFPE handbook of fire protection 
engineering. Springer, New York, NY, 2016, pp. 2552-2590.

[4] D. Drysdale. An introduction to fire dynamics. John Wiley \& Sons, 2011.

[5] G. Landucci, G. Gubinelli, G. Antonioni, et al. The assessment of the damage probability of storage tanks in domino events triggered by fire. Accident Anal. Prev., 41(6)(2009), pp. 1206-1215.

[6] Z. Ni, Y. Wang, Z. Yin. Relative risk model for assessing domino effect in chemical process industry. Safety Sci., 87(2016), pp. 156-166.

[7] D.W. Hissong. Keys to modeling LNG spills on water. J. Hazard. Mater., 140(3)(2007), pp. 465-477.

[8] F. Briscoe, P. Shaw. Spread and evaporation of liquid. Prog. Energy Combust. Sci., 6(2)(1980), pp. 127-140.

[9] J. Ji, X. Yuan, K. Li, et al. A mathematical model for burning rate of n-heptane pool fires under external wind conditions in long passage connected to a shaft. Appl. Therm. Eng., 116(2017), pp. 91-99.

[10] B.D. Ditch, J.L. de Ris, T.K. Blanchat, et al. Pool fires-An empirical correlation. Combust. Flame, 160(12)(2013), pp. 2964-2974.

[11] M. Benfer. Spill and Burning Behavior of Flammable Liquids. Master Dissertation, School of Maryland, 2010.

[12] Y. Li, H. Huang, Z. Wang, et al. An experimental and modeling study of continuous liquid fuel spill fires on water. J. Loss Prev. Process Ind., 33(2015), pp. 250-257.

[13] Y. Li, H. Huang, J. Zhang, et al. Large-scale experimental study on the spread and burning behavior of continuous liquid fuel spill fires on water. J. Fire Sci., 32(5)(2014), pp. 391-405.

[14] S. Raja, T. Abbasi, S.M. Tauseef, et al. Equilibrium models for predicting areas covered by accidentally spilled liquid fuels and an assessment of their efficacy. Process. Saf. Environ., 130(2019), pp. 153-162.

[15] H. Ingason, Y.Z. Li. Spilled liquid fires in tunnels. Fire Safety J., 91(2017), pp. 399-406.

[16] Y. Li, H. Huang, L. Zhang, et al. An experimental investigation into the effect of substrate slope on the continuously released liquid fuel spill fires. J. Loss Prev. Process 
Ind., 45 (2017): pp. 203-209.

[17] J. Zhao, Q. Liu, H. Huang, et al. Experiments investigating fuel spread behaviors for continuous spill fires on fireproof glass. J. Fire Sci., 35(1)(2017), pp.80-95.

[18] Y. Lin, M.A. Delichatsios, X. Zhang, et al. Experimental study and physical analysis of flame geometry in pool fires under relatively strong cross flows. Combust. Flame, 205(2019), pp. 422-433.

[19] V. Babrauskas. Estimating large pool fire burning rates. Fire Technol., 19(4) (1983), pp.251-261.

[20] D.W. Johnson, J.B. Cornwell. Modeling the release, spreading, and burning of LNG, LPG, and gasoline on water. J. Hazard. Mater., 140(2007), pp. 535-540.

[21] W. Lehr, D. Simecek-Beatty. Comparison of hypothetical LNG and fuel oil fires on water. J. Hazard. Mater., 107(2004), pp. 3-9.

[22] J.M. Raisbeck, M.F. Mohtadi. The environmental impacts of oil spills on land in the arctic regions. Water Air Soil Poll., 3(2)(1974), pp. 195-208

[23] M. Hussein, M. Jin, J.W. Weaver. Development and verification of a screening model for surface spreading of petroleum. J. Contam. Hydrol., 57 (2002), pp281-302. [24] C.S. Simmons, J.M. Keller, J.L. Hylden. Spills on flat inclined pavements. Department of Energy, United States, 2014.

[25] T. Abbasi, V. Kumar, S.M. Tauseef, et al. Spread rate of flammable liquids over flat and inclined porous surfaces. J. Chemical Health and Safety, 25(5)(2018), pp. 1927.

[26] A. Sharma, K.B. Mishra. Experimental set-up to measure the maximum mass burning rate of storage tank fires. Porcess Saf. Environ., 131(2019), pp.282-291.

[27] H.W.M. Witlox. Model for pool spreading, evaporation and solution on land and water (PVAP)-Theory Manual, Consequence modeling documentation (PHAST Technical Reference), 2000.

[28] J. Zhao, H. Huang, Y. Li, et al. Quantitative risk assessment of continuous liquid spill fires based on spread and burning behaviors. Appl. Therm. Eng., 126(2017), pp. 500-506.

[29] D.S. Burgess, A. Strasser, J. Grumer. Diffusive burning of liquid fuels in open trays. 
$510 \quad$ Fire Res. Abstr. Rev., 1961.

511 [30] A. Hamins, S.J. Fischer, T. Kashiwagi, et al. Heat feedback to the fuel surface in 512 pool fires. Combust. Sci. Technol., 97(1-3)(1994), pp. 37-62.

513 [31] J.M. Suo-Anttila, T.K. Blanchat, A.J. Ricks, et al. Characterization of thermal 514 radiation spectra in $2 \mathrm{~m}$ pool fires. Combustion Inst., 32 (2009), pp. 2567-2574.

515 [32] J. Zhao, H. Huang, H. Wang, et al. Experimental study on burning behaviors and 516 thermal radiative penetration of thin-layer burning. J. Therm. Anal. Calorim., 130 517 (2017), pp. 1153-1162.

518 [33] G. Kirstetter, J. Hu, O. Delestre, et al. Modeling rain-driven overland flow: 519 Empirical versus analytical friction terms in the shallow water approximation. J. 520 Hydrol., 536(2015), pp. 1-9.

521 [34] J.R. Lister. Viscous flows down an inclined plane from point and line sources. J. 522 Fluid Mech., 242(1992), pp. 631-653.

523 [35] B. McCaffrey, Flame Height. The SFPE Handbook of Fire Protection Engineering, 524 2nd ed., Society of Fire Protection Engineers and National Fire Protection Association, 525 Quincy, MA, 1995. 